\title{
Self-reported Oral and Dental Health Status among the Pregnant Women of A Selected Hospital in Dhaka City
}

\begin{abstract}
MR Hasan', AB Dithi' ${ }^{2}$, NA Nomann ${ }^{3}, \mathrm{~J} \mathrm{Nessa}^{4}$, T Saito $^{5}$
Abstract

Aims: The aims of this study were to gain an understanding of pregnant women's oral hygiene practices and to assess the oral and dental health status.

Materials and Methods: A semi - structured questionnaire was completed by 100 pregnant women of the gynecology department of Dr. Akhter Jahan Mirza Hospital, Dhaka.

Results: The women in this study 40\% were in 19-22 years age group. Forty eight percent (48\%) women of the subjects were having up to high school level education \& $28 \%$ had low income of Sixty Thousand to One Lac taka yearly. In relation to oral hygiene habit before pregnancy majority of the women (56\%) stated that they brush their teeth once a day, $19 \%$ use dental floss and $14 \%$ use mouth rinse once a day. During pregnancy women seemed to be slightly more concerned about oral hygiene but not significantly. Only $66 \%$ brush their teeth and $17 \%$ floss their teeth and $18 \%$ use mouth rinse once a day during pregnancy. The major problem in their mouth noticed by the women during pregnancy was bleeding gums (58\%).
\end{abstract}

Conclusion: This study feels the necessity of giving special attention to pregnant women's oral health in Bangladesh. Women should be educated on good oral hygiene practices so as to minimize prevalence of poor maternal oral health during pregnancy.

Key words: Pregnancy, Oral hygiene, Dental knowledge.

\section{Introduction}

Pregnancy is a unique time in women's life and is characterized by complex physiological changes. These changes can adversely affect oral health.

1. Dr. Md. Riasat Hasan, BDS, MPH, FRSPH (UK), Doctoral Fellow, Division of Clinical Cariology and Endodontology, Department of Oral Rehabilitation, School of Dentistry, Health Sciences University of Hokkaido, Japan.

2. Dr. Akashlynn Badruddoza Dithi, BDS, Doctoral Fellow, Division of Biomaterials and Bioengineering, Department of Oral Rehabilitation, School of Dentistry, Health Sciences University of Hokkaido, Japan.

3. Dr. Nahid Al Nomann, BDS, Doctoral Fellow, Division of Clinical Cariology and Endodontology, Department of Oral Rehabilitation, School of Dentistry, Health Sciences University of Hokkaido, Japan.

4. Dr. Jebun Nessa, BDS, DDS, DPHC, MPH (Australia), Associate Professor\& Head, Department of Preventive \& Children Dentistry, Bangabandhu Sheikh Mujib Medical University (BSMMU), Dhaka, Bangladesh.

5. Prof. Dr. Takashi Saito, $\mathrm{DDS}, \mathrm{PhD}$, Division of Clinical Cariology and Endodontology, Department of Oral Rehabilitation, School of Dentistry, Health Sciences University of Hokkaido, Japan.

Address of Correspondence:

Dr. Md. Riasat Hasan BDS, MPH, FRSPH (UK)

Division of Clinical Cariology and Endodontology, Department of Oral Rehabilitation, School of Dentistry, Health Sciences University of Hokkaido, 1757 Tobetsu, Hokkaido 061-0293, Japan.

E-mail: riasat@hoku-iryo-u.ac.jp
Therefore, the pregnant population group requires special care in terms of oral health care including nutrition. Pregnancy has no direct causation on tooth loss, but there are a number of factors that influence the rapidity and progression of incipient or already well-established oral disease. The expectant mother may be involved in a multitude of extra activities, which can lead to a neglect of her own oral care and can result in dental problems which require extra attention during this phase.

Hormonal changes during pregnancy have been suggested to predispose women to gingivitis, affecting $35-100 \%$ of pregnant women ${ }^{15}$. Mainly because of estrogen, the gum become inflamed, edematous, and sensitive, with a tendency to bleed easily, and existing gingivitis may worsen considerably during pregnancy if plaque is not removed ${ }^{4,8}$. Furthermore, advanced periodontal infections in pregnant women may pose a threat to the placenta and uterus and may increase the likelihood of pre-term delivery ${ }^{3,14}$. It has been estimated that periodontal disease of the mother might cause more than $18 \%$ of all pre-term births and low birth weight in infants ${ }^{14}$.

Support for dental treatment in governmental hospitals is not enough in district levels in Bangladesh. Mothers and children welfare center (MCWC) is a sister organization of Bangladesh government under the Ministry of Health and Family Welfare, where the antenatal women come for regular checkup. 
They have dental problems but in MCWCs have no support for dental treatment ${ }^{12}$.

It has been recommended that all women should bave a dental examination and appropriate dental hygiene care at least once during their pregnancy ${ }^{1}$. However, many women in a number of countries do not visit a dentist during their pregnancy $5,6,11$. Therefore oral and dental health care practices and knowledge of pregnant women in Bangladesh should be assessed as a high risk group.

So, this study was planned to describe the self-reported oral hygiene practices and to assess the oral and dental health status among the pregnant women in gynecology department of Dr, Akhter Jahan Mirza Hospital, Dhakka, Bangladesh.

\section{Materials and Mathods}

A descriptive cross - sectional study was carried out among pregnant women attending at gynecology department of Dr. Akhter Jahan Mirza Hospital, Dhaka. The sample size was 100 pregnant women. The time period of the study was limited to six months. Within this period, eight weeks were spent for data collection and the rest of the period were spent for anslysis, report writing and submission. Purposive sampling technique was followed for selection of the study women. A semi-structured questionnaire was developed following a pilot study in a small similar study population. The one-to-one interview was taken as per the printed questionnaire. Security and confidentiality was maintained by taking appropriate cure and sincerity of interviewers and the researcher as per ethical consideration of the research. After completion of data collection all questionnaires were filed up, statistical softwarc SPSS (vesion 15.0) was used to enter data for analysis. Prior to commencement of the study, ethical clearance was taken from Ethical Review Committee (ERC, No. 10-91195) of American International University-Bangladesh (AIUB).

\section{Revults}

A total of 100 pregnart women were examined. The age groups were divided into five categories, of which $40 \%$ were in the age group of 19-22 years. Others were $15-18$ years $16 \%$, $23-27$ years $15 \%, 28-35$ years $17 \%$, and $35+$ years age $12 \%$. [Figure-1]

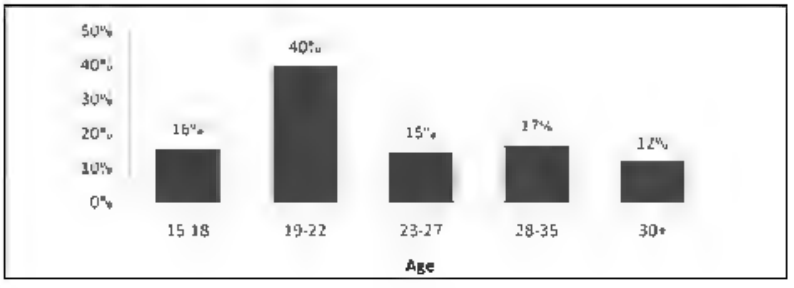

Figure -1 Difterent Age group
The education groups were divided into "less than high scbool" category (which includes ability to sign own name to primary school level), "high school" category (which includes class 6 to SSC pass) "diploma", "graduate" and "postgraduate" category. Almost half of the women studied had less than High School education (48\%) [Figure-2].

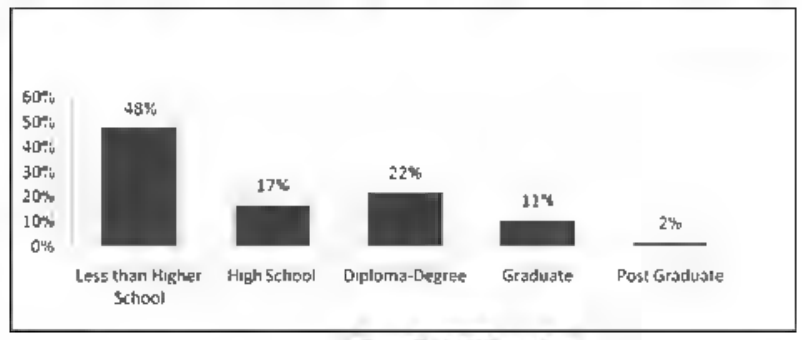

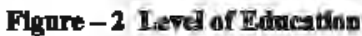

About household income, $28 \%$ of the study women had a low (60,000-1 lac taka) annual income and 26\% did not know their household income [Figure-3].

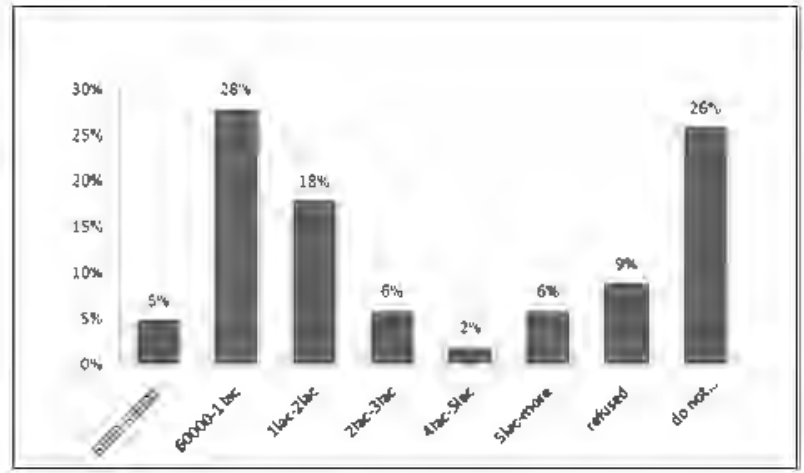

Figure 3 Annusl Family Incomes

In non-pregnant stage $56 \%$ and during pregnant stage $66 \%$ stated that they brush their teeth once a day and also it was found that $58 \%$ of the women in non-pregnant stage and $52 \%$ of women in pregnant stage never flossed their teeth, $14 \%$ of the women used mouth wash in non-pregnant stage and $18 \%$ in pregnant stage. However, comparing the dental hygiene before and during their pregnancy period it shows that during pregnancy women seemed to be slightly more concerned sbout oral hygiene but not significantly [Table-1].

Table-1 The orol hygiene status before and during pregnancy period

\begin{tabular}{|c|c|c|}
\hline Varlehle: & Before preguancy & Current Pregnancy \\
\hline Fow oflen breh your terth & Poreenture & Percenterate \\
\hline Twice or mare a day & 19 & 29 \\
\hline Once a day & 56 & 66 \\
\hline Not every day & 25 & 5 \\
\hline \multicolumn{3}{|l|}{ How often floes your teoth } \\
\hline Twice or mare a day & $\mathbf{8}$ & 12 \\
\hline Once a dey & 19 & 17 \\
\hline Not every day & 15 & 19 \\
\hline Nover & 58 & 52 \\
\hline \multicolumn{3}{|l|}{ Uat mouth rince } \\
\hline Yel & 14 & 18 \\
\hline No & 86 & 82 \\
\hline
\end{tabular}


The major problem in their mouth noticed by the women during pregnancy was bleeding gums $58 \%$, toothache $13 \%$, cavities $7 \%$, and sensitive teeth $4 \%$ [Figure-4].

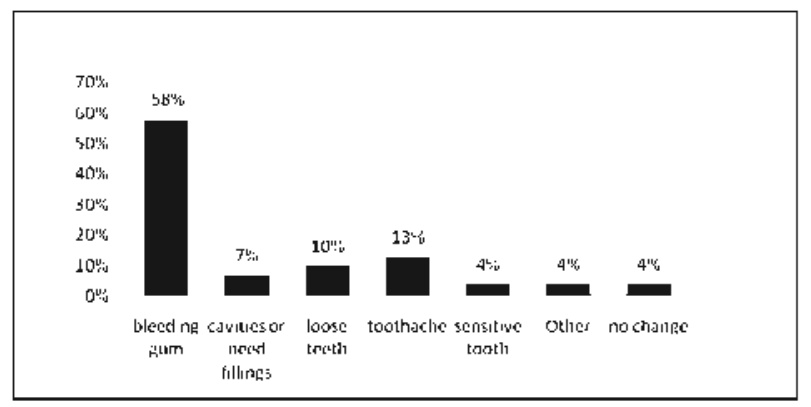

Figure - 4 Changes in teeth/gum during pregnancy

\section{Discussion}

A number of self-reported studies around the world have investigated about the level of dental care, dentral health aceess and knowledge about dental health and their relationship with pregnency outcomes $2,5,7,9,16$.

So far this is the first study in Bangladesh adopting a similar approach. Previously, Makowharemahihi presented a thesis on "A community-based health needs assessment of the oral health needs of Maori mothers in Porirua", in which she extrapolated through a qualitative study the needs of a group of Maori mothers ${ }^{10}$.

The present study, sought to provide more broadly quantitative information about expectant mothers in the gynae department of Dr. Akhtar Jahan Mirza Hospital, Dhaks. The main finding of this research on pregnant women participating in this study presented with poor oral hygiene habits, more than half of the women reported bleeding gums during pregnancy. The first objective of this research was to analyze oral health care practices and behavior of women before and during pregnancy, and whether these changed during this period. This was achieved through a series of questions relevant to dentistry including oral hygiene.

In this study, most women reported "fair" \& "poor" oral hygiene, brush their teeth one time per day, use floss and mouth wash occasionally. Their hygiene pattern did not change significantly during pregnancy, with $29 \%$ brush their teeth twice or more per day, $12 \%$ flossed their teth once a day and $18 \%$ using mouth rinse. Other international studies show similar findings of oral bygiene during pregnancy, but these studies did not compare this with aral hygiene practices before pregnancy 7,15 .
The main change and/or problems related to mouths that were reported by women during pregnancy were bleeding gums, followed by sensitive teeth and others (such as infections or broken teeth). It is important to note that $58 \%$ of women in this study noticed hleeding gums during pregnancy. Similar findings were observed in the Australian study ${ }^{16}$ where $60 \%$ of the women stated that they had gums bleeding at some stage during the previous 12 months. Bleeding gums is nommally one of the first signs of gingivitis and is common among pregnant women due to hormonal changes in this period which accentuate the gum's response to plaque. It is important to point out that pregnancy does not cause gingivitis, but may aggravate pre-existing disease. However, gingivitis can progress to periodontitis (loss of connective tissue) $)^{13}$ and, according to a number of studies; can be associated with birth outcomes ${ }^{14}$ aueh as low birth weight, preterm birth and preeclampsia. Similar frequencies were observed in a number of international researches, $30 \%$ in Australie ${ }^{16}$, a range of $25-50 \%$ in American studies 5,9 .

There is a lack of formal guideline about oral health for pregnant women in Bangladesh, which could be beneficial for public and health professionals to inform pregnant woman about the best practices regarding this topic. The other sources of information for pregnant woman in our study were dental healthcare workers and maternity careers.

Finally, there is a lack of integration between dentistry and other professional areas such as matemity care workers, who do not normally cover this topic with their patients. Sometimes dentists are insecure about the management of pregnant patients and don't take the opportunity to promote preventative measures.

The vast majority of women receive antenatal care from midwifes, obstetrician and attend antenatal classes. Thus, maternity careers are in a strategic position to provide counseling to pregnant women regarding oral health. Women could be advised to see the dentist before becoming pregnant and visit the dentist and other dental health workers during pregnancy, especially for checkup and cleaning. They should be advised to brush their tecth at least twice a day, floss at least once a day and have a balanced diet avoiding excessive amount of sugary snack. 


\section{Conclusions}

This study feels the necessity of special attention to pregnant women's oral health in Bangladesh. From this study, we can conclude that majority of the pregnant women had a poor level of oral hygiene with gingivitis. So, dental health education programs should be carried out at regular intervals to impart knowledge on dental health and oral hygiene practices. The dentist should be consulted as early as possible in the first stages of pregnancy for a thorough examination so that all necessary treatments can be carried out well in advance.

\section{References}

1. Carl, D. L., Roux, G. \& Matacale, R. Exploring dental hygiene and perinatal outcomes: oralhealthimplicationsforpregnancy and early childhood. AWHONN Lifelines, 4 : 22-27, 2000.

2. Christensen, L., Jeppe-Jensen, D., \& Petersen, P. Self-reported gingival conditions and self-care in the oral health of Danish women during pregnancy. Journal of Clinical Periodontology, 30 : 949-953, 2003.

3. Dasanayake, A. P. Poor periodontal health of the pregnant woman as a risk factor for low birth weight. Annals of Periodontology, 3 : 206-212, 1998.

4. Ferris, G. M. Alteration in female sex hormones: their effect on oral tissues and dental treatment. Compendium on Continuing Education of Dentistry, 16 : 1558-1571, 1993.

5. Gaffield, M. L., Colley Gilbert, B. J., Malvitz, D. M. \& Romaguera, R. Oral health during pregnancy. Ananalysis of information collected by the Pregnancy Risk Assessment Monitoring System. Journal of the American Dental Association, 132 : 1009-1016, 2001.

6. Gunay, H., Goepel, K., Stock, K. H. \& Schneller, T. Position of health education knowledge concerning pregnancy. Oralprophylaxe, $13: 4-7$ (in German), 1991.

7. Honkala, S., \& Al-Ansari. Self-reported oral health, oral hygiene habits, and dental attendance of pregnant women in Kwait. Journal of Clinical Periodontology, 32 : 809- 814, 2005.
8. Loe, H. \& Silness, J. Periodontal disease in pregnancy. Acta Odontologica Scandinavica, 21 : 533-551, 1963.

9. Lydon-Rochelle, M., Krakowiak, P., Hujoel, P., \& Peters, R. Dental care use and selfreported dental problems in relation to pregnancy. American Journal of Public Health, 94 : 765-771, 2004.

10. Makowharemahihi, C. A community-based health needs assessment of the oral health needs of Maori mothers in Porirua. University of Otago, Wellington, 2006.

11. Mangskau, K. A. \& Arrindell, B. Pregnancy and oral health: utilization of the oral health care system by pregnant women in North Dakota. Northwest Dentistry, 75 : 23-28, 1996.

12. Md Mahafuzur, R., Md Riasat, H., Md Ziaul, I. Oral Health Status of Pregnant Women attended the Mothers and Children Welfare Center (MCWC) in Bangladesh. City Dent. Coll. J Volume-10, Number-2, 01-04, July-2013.

13. Murray, J., Nunn, J., \& Steele, J. (Eds.). Prevention of Oral Disease (four ed.). NewYork: Oxford University Press, 2003.

14. Offenbacher, S., Katz, V., Fertik,G., Collins,J., Boyd,D., Maynor,G., McKaig,R. \& Beck,J. Periodontal infection as a possible risk factor for preterm low birth weight. Journal of Periodontology, 67 : 1103-1113, 1996.

15. Raber-Durlacher, J. E., van Steenbergen, T. J. M., van der Velden, U. \& de Graff, J. Experimental gingivitis during pregnancy and post-partum: clinical, endocrinological and microbiological aspects. Journal of Clinical Periodontology, 21 : 549-558, 1994.

16. Thomas $N$, Middleton $P, \&$ Crowther $C$. Oral and dental health care practices in pregnant women in Australia: a postnatal survey. Biomed Central Pregnancy and Childbirth, 8(13), 1-6. 2008. 